\title{
Hygroscopic growth and droplet activation of soot particles: uncoated, succinic or sulfuric acid coated
}

\author{
S. Henning ${ }^{1}$, M. Ziese ${ }^{1, *}$, A. Kiselev ${ }^{1, * *}$, H. Saathoff ${ }^{2}$, O. Möhler ${ }^{2}$, T. F. Mentel ${ }^{3}$, A. Buchholz ${ }^{3}$, C. Spindler ${ }^{3}$, \\ V. Michaud ${ }^{4}$, M. Monier ${ }^{4}$, K. Sellegri ${ }^{4}$, and F. Stratmann ${ }^{1}$ \\ ${ }^{1}$ Institute for Tropospheric Research, 04318 Leipzig, Germany \\ ${ }^{2}$ Karlsruhe Institute of Technology, 76131 Karlsruhe, Germany \\ ${ }^{3}$ Forschungszentrum Jülich, 52425 Jülich, Germany \\ ${ }^{4}$ Laboratoire de Météorologie Physique, Université Blaise Pascal, 63177 Aubière Cedex, France \\ *now at: Deutscher Wetterdienst, 63067 Offenbach/M., Germany \\ ** now at: Karlsruhe Institute of Technology, 76131 Karlsruhe, Germany
}

Correspondence to: S. Henning (henning@tropos.de)

Received: 5 October 2011 - Published in Atmos. Chem. Phys. Discuss.: 21 October 2011

Revised: 30 April 2012 - Accepted: 5 May 2012 - Published: 24 May 2012

\begin{abstract}
The hygroscopic growth and droplet activation of uncoated soot particles and such coated with succinic acid and sulfuric acid were investigated during the IN-11 campaign at the Aerosol Interaction and Dynamics in the Atmosphere (AIDA) facility. A GFG-1000 soot generator applying either nitrogen or argon as carrier gas and a miniCAST soot generator were utilized to generate soot particles. Different organic carbon (OC) to black carbon (BC) ratios were adjusted for the CAST-soot by varying the fuel to air ratio. The hygroscopic growth was investigated by means of the mobile Leipzig Aerosol Cloud Interaction Simulator (LACIS-mobile) and two different Hygroscopicity Tandem Differential Mobility Analyzers (HTDMA, VHTDMA). Two Cloud Condensation Nucleus Counter (CCNC) were applied to measure the activation of the particles. For the untreated soot particles neither hygroscopic growth nor activation was observed at a supersaturation of $1 \%$, with exception of a partial activation of GFG-soot generated with argon as carrier gas. Coatings of succinic acid lead to a detectable hygroscopic growth of GFG-soot and enhanced the activated fraction of GFG- (carrier gas: argon) and CAST-soot, whereas no hygroscopic growth of the coated CAST-soot was found. Sulfuric acid coatings led to an OC-content dependent hygroscopic growth of CAST-soot. Such a dependence was not observed for activation measurements. Coating with sulfuric acid decreased the amount of Polycyclic Aromatic Hydrocarbons (PAH), which were detected by AMS-measurements in
\end{abstract}

the CAST-soot, and increased the amount of substances with lower molecular weight than the initial PAHs. We assume that these reaction products increased the hygroscopicity of the coated particles in addition to the coating substance itself.

\section{Introduction}

Atmospheric aerosol particles interact with solar radiation directly by scattering and/or absorbing it and indirectly by acting as Cloud Condensation Nuclei $(\mathrm{CCN})$ and by changing cloud microphysical properties. Due to human activities the number of aerosol particles in the atmosphere has increased (Seinfeld and Pandis, 2006), which led also to an increased number of potential CCNs. Cloud properties such as the number and size of droplets depend on the CCN number and also on water vapor available. This may cause also changes in precipitation, cloud lifetime (Albrecht, 1989) and cloud albedo, known as the Twomey effect (Twomey, 1974). The atmospheric aerosol consists of many different particle types, e.g., sea salt, pollen, mineral dust or soot. We here focus on the hygroscopic and $\mathrm{CCN}$ properties of soot particles and their respective modification in mixtures with sulfuric and succinic acid. The latter to simulate chemical ageing by inorganic and organic compounds in the atmosphere.

Soot particles are agglomerates of carbon containing particles, which are formed during incomplete combustion 
processes (Seinfeld and Pandis, 2006). Soot particles contain absorbing graphite like carbon (black carbon, $\mathrm{BC}$ ) and at the same time many other carbon containing substances (organic carbon, OC). From a morphological point of view, soot particles are fractals. They consist of chains of primary particles with internal voids, which may compact due to wetting with water or other fluids.

The annual global emission of $\mathrm{BC}$ is estimated to $8.0 \mathrm{Tg}$ for $\mathrm{BC}$ and 33.9 Tg for OC (Bond et al., 2004; Cooke and Wilson, 1996; Cooke et al., 1999; Horvath, 1993; Ito and Penner, 2005; Juncker and Liousse, 2008; Kim et al., 2008; Kanakidou et al., 2005; Novakov et al., 2003; Penner et al., 1993; Tegen et al., 2000), with the largest source of both being biomass burning ( $42 \%$ of $\mathrm{BC}$ and $74 \%$ of OC). The remaining fraction of $\mathrm{BC}$ emissions is dominated by transport, industry, and the residential sector with $20 \%, 10 \%$ and $25 \%$, respectively. Besides biomass burning, the emissions from residential solid fuels contribute nearly $20 \%$ and transport $4 \%$ to the global budget of OC (Bond et al., 2004).

The residence time of soot particles in the atmosphere is about seven days and $98 \%$ of the soot particles are removed by precipitation (Jacobson, 2004). That is long enough to transport the particles hundreds to thousands of kilometers, but too short for an interhemispheric transport (Horvath, 1993). During transport in the atmosphere soot particles undergo aging processes, e.g. due to condensation, which alter their cloud forming potential (Andreae and Rosenfeld (2008) and references therein).

At relative humidities lower than $95 \%$ investigations regarding the hygroscopic growth of soot particles were performed by several groups. Meyer and Ristovski (2007), Weingartner et al. (1997) and Tritscher et al. (2011) for example investigated diesel soot and Gysel et al. (2003) soot from aviation fuel. The reported growth factors (GF, defined as the measured wet diameter divided by the selected dry diameter) for these soot types ranged between 1 and 1.19 $\left(\mathrm{RH}=95 \%, d_{p, 0}=50 \mathrm{~nm}\right)$. The GF increased with increasing sulfur content of the fuel. Weingartner et al. (1997) and Henning et al. (2010) used the same type of spark generator with nitrogen as carrier gas as was used in this study. They observed no hygroscopic growth for the uncoated spark soot, but after coating with soluble substances a hygroscopic growth occurred (Henning et al., 2010). Khalizov et al. (2009) and Zhang et al. (2008) investigated the hygroscopic growth of sulfuric acid coated flame soot up to $90 \%$ relative humidity (RH). They found growth factors up to 1.5 and a decrease in GF with increasing selected mobility diameter.

The activation of soot particles was investigated by Lammel and Novakov (1995); Tritscher et al. (2011) using diesel soot, by Hitzenberger et al. (2003); Hudson et al. (1991); Pitchford et al. (1991) using soot generated via the combustion of aviation fuel, by Hagen et al. (1989) using soot from white gas and ethanol combustion and by Hudson et al. (1991) using soot from different wood types and crude oil. The particles were found to activate better with increas- ing sulfur content of the fuel. No (complete) activation was found for soot from aviation fuel, wood and crude oil. Henning et al. (2010) observed, that coated spark soot acts as $\operatorname{CCN}\left(d_{p, 0}=85 \mathrm{~nm}\right.$ activated between 0.3 and $\left.0.6 \%\right)$. Zhang et al. (2008) investigated the activation of sulfuric acid coated flame soot at two supersaturations $(0.2$ and $0.4 \%)$, but they found no activation for the uncoated soot at the same supersaturations.

The IN-11 measurement campaign at the AIDA was carried out to get comprehensive data regarding hygroscopic growth, cloud droplet activation and ice nucleation potential, which is required to determine the importance of fresh and aged soot particles in cloud formation and freezing. The mobile version of the Leipzig Aerosol Cloud Interaction Simulator (LACIS-mobile, IfT home-built), a Hygroscopicity Tandem Differential Mobility Analyzer (HTDMA, Buchholz, 2007) and a Volatility Hygroscopicity Tandem Differential Mobility Analyzer (VHTDMA, LaMP home-built) were applied to investigate the hygroscopic growth up to $98.4 \%$ $\mathrm{RH}$ as well as two Cloud Condensation Nucleus Counters (CCNC, DMT, Boulder, CO, USA, Roberts and Nenes, 2005) for activation measurements between 0.14 and $1.54 \%$ supersaturation. The ice formation potential as discussed in Crawford et al. (2011), was investigated applying the AIDAchamber (Möhler et al., 2001). Soot particles were generated by means of either a flame soot generator (miniCAST, Jing-CAST Technology GmbH, Switzerland, Jing, 2000) or a spark soot generator (GFG-1000, Palas GmbH, Karlsruhe, Germany, Helsper et al., 1993). These soot particles were investigated pure, and after being coated with either succinic acid or sulfuric acid.

\section{Experimental setup}

The experiments were conducted in the framework of the AIDA infrastructure at the Karlsruhe Institute for Technology in order to collect comprehensive data for the hygroscopic growth, cloud droplet activation and ice forming potential of different kinds of soot particles. The setup is shown schematically in Fig. 1 and described in the following.

Experiments were typically conducted according to the following cycle: the soot particles were generated by utilizing either the miniCAST or the GFG generator. Afterwards the particles were either coated or used without any treatment. A small aerosol chamber (NAUA chamber, $3.9 \mathrm{~m}^{-3}$ ) was used as aerosol reservoir for the whole experiment. Aerosol was fed into the NAUA chamber until a number concentration of around $10^{4}-10^{5} \mathrm{~cm}^{-3}$ was reached. Afterwards the AIDA chamber was filled with a part of the aerosol from the NAUA chamber, which was refilled with particle free dry synthetic air to regain atmospheric pressure inside. Thereafter, the NAUA chamber was available as aerosol source for all other instruments (Fig. 1). The residence time of the aerosol in the NAUA chamber ranged depending on 


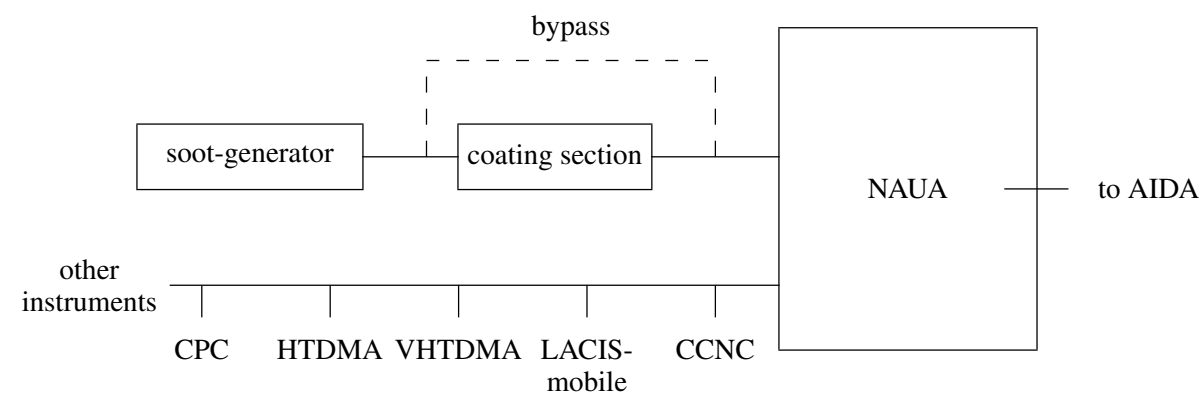

Fig. 1. Experimental setup.

Table 1. Experimental settings of NAUA experiments during IN-11.

\begin{tabular}{lcccccc}
\hline $\begin{array}{l}\text { NAUA } \\
\text { Experiment }\end{array}$ & Generator & Carrier gas & OC-content & Coating substance & $\begin{array}{c}\text { Aerosol flow saturator } \\
\left(1 \mathrm{~min}^{-1}\right)\end{array}$ & $\begin{array}{c}T \text { saturator } \\
\left({ }^{\circ} \mathrm{C}\right)\end{array}$ \\
\hline $1,2,4$ & GFG & Argon & & Uncoated & \\
3 & GFG & Nitrogen & & Uncoated & & 90 \\
6 & GFG & Argon & & Succinic acid & 5 & \\
7 & miniCAST & & minOC & Uncoated & & \\
15 & miniCAST & & medOC & Uncoated & & $90 / 95$ \\
10 & miniCAST & & maxOC & Uncoated & 5 & 55 \\
16,17 & miniCAST & & medOC & Succinic acid & 5 & $70 / 95$ \\
9 & miniCAST & & minOC & Sulfuric acid & 5 & 45 \\
13,14 & miniCAST & & medOC & Sulfuric acid & $2 / 5$ & 1 \\
12 & miniCAST & & maxOC & Sulfuric acid & & 45 \\
\hline
\end{tabular}

the experiment between 2 and $9 \mathrm{~h}$. During aerosol sampling NAUA was permanently refilled with synthetic air to hold the pressure at atmospheric levels. The aerosol in the NAUA was polydisperse, but all measurements presented here were done for diffusion dried size-selected particles. The number concentration of the size-selected particles was detected with a CPC 3010 (TSI, Aachen, Germany).

An overview of all conducted experiments including the generation and coating settings is given in Table 1 .

\subsection{Particle generation}

Two soot types were investigated, generated by means of the two (see below) different soot generators. One was a graphite spark soot generator (Helsper et al., 1993) with either nitrogen or argon as carrier gas (purity 6.0, from now on referred to as "GFG-soot"). The carrier gas was varied, because earlier measurements suggested an influence of the carrier gas on the hygroscopic properties of GFG-soot. The OC-content of the GFG-soot was $12 \pm 9 \mathrm{wt} \%$.

The second was a miniCAST flame soot generator (from now on referred to as "CAST-soot" Jing, 2000). The OCcontent of the CAST-soot was adjusted by the fuel (propane) to air ratio, leading to particles with high OC-content (>80 wt $\%$, max OC), medium OC-content $(78 \pm 2 \mathrm{wt} \%$, med OC) and low OC-content ( $32 \pm 4 \mathrm{wt} \%$, min OC). The OCcontent was determined following VDI 2465 (1999), consid- ering material as organic carbon which is volatile in helium at temperatures below or equal $600^{\circ} \mathrm{C}$.

The soot aerosol was diluted before entering the coating section $1 / 100$ by means of two PALAS dilution systems (VKL 10, PALAS GmbH, Karlsruhe, Germany).

\subsection{Coating section}

For the soot particle coating, a flow of particle-free synthetic air was saturated with the coating substance at the temperature given in Table 1, then further heated to the mixing zone temperature, which was about $10 \mathrm{~K}$ higher than the saturator temperature. The aerosol flow was heated to the same temperature and added to the mixing zone. Afterwards the temperature of the aerosol-gas-mixture was reduced continuously down to about room temperature to condense the coating substance on the particles.

Succinic acid and sulfuric acid were used as coating substances. Succinic acid was chosen as an example for an oxygenated organic substance to mimic soot aged in biogenically influenced environments. Succinic acid is found frequently in the atmospheric aerosol (Chebbi and Carlier, 1996). It features a low vapor pressure $\left(10^{-3} \mathrm{~Pa}\right.$ at $\left.25^{\circ} \mathrm{C}\right)$ and moderate solubility (83.2 $\mathrm{g} \mathrm{l}^{-1}$ at $25^{\circ} \mathrm{C}$; Bilde et al., 2003; Howard and Meylan, 1997).

Sulfuric acid is formed in the atmosphere via oxidation of $\mathrm{SO}_{2}$, which is emitted by e.g. combustion of sulfur 
containing fuels (Seinfeld and Pandis, 2006). Soot particles coated with sulfuric acid are a model aerosol for particles, which are aged in anthropogenically influenced regions.

\subsection{Particle morphology and growth factor definition}

Soot particles used in this study are loose aggregates consisting of several to several hundreds of primary particles. Depending on the generation method, these primary particles have a different characteristic size: either a few nanometers in the case of spark-discharge generation (GFG-soot) or around $30 \mathrm{~nm}$ for the premixed flame generator (miniCAST). The most striking feature of such aggregates is the arrangement of the primary particles into a so called fractal cluster, which can be described by a scaling relationship between the number of primary particles in the cluster and its geometrical size (Schmidt-Ott, A., 1988; Wiltzius, 1987). Due to their looseness these aggregates exhibit a reduced mechanical stability and are subject to restructuring at condensation of the coating substance resulting in more compact aggregates characterized by a higher value of fractal dimension $D_{f}$. In previous studies incomplete restructuring of GFG-soot due to the coating with ammonium sulfate and levoglucosan was observed and characterized using tandem measurements of mobility and aerodynamic equivalent diameters of soot prior to and after restructuring (Kiselev et al., 2010). The collapse of GFGsoot particles due to the coating with sulfuric acid was also previously reported by Möhler et al. (2005). Summarizing these studies, the coating by condensation is always accompanied by restructuring of originally loose aggregates with simultaneous filling of the voids formed by collapsing aggregate branches. However, depending on the degree of coatinginduced restructuring, the further restructuring of soot due to the condensation of water may take place (Mikhailov et al., 1999).

This shows that the restructuring of soot aggregates may have a significant effect on the observed condensational growth rate of soot particles. A possible way to avoid the systematic error, introduced by not taking into account the restructuring phenomena, would be to use the volume equivalent diameter for the characterization of the dry soot aggregates, as compared to the mobility diameter (Tritscher et al., 2011). However, this approach does not eliminate the uncertainty introduced by the presence of voids in partially compacted soot aggregates: due to the complex nature of the restructuring process neither the void fraction nor the accessibility of voids for condensing water is known. For example, using the total volume of bulk matter (i.e., summing up the volumes of all primary particles) in a soot aggregate to calculate its volume equivalent diameter would underestimate its dry "envelope" diameter (a quantity that will be measured by any non-optical aerosol instrument) by almost $40 \%$ (accounting for the random packing of primary particles that gives in the best case a packing factor of 0.63). More correctly would be to define the GF as a mass growth factor (as a ratio of mass grown due to condensation to the mass of the dry particle), but its evaluation is even less realistic since the recalculation of the mobility diameter into the mass equivalent diameter can hardly be done without additional morphological information (size distribution of the primary particles of the soot agglomerates, fractal dimension before and after coating, mass fraction of the coating substance, degree of restructuring due to coating, etc.), which was not available during the IN-11 experiment described here.

Lacking this particular information needed for characterization of soot morphology, we were forced to define the growth factor (GF) as the measured wet diameter divided by the selected dry mobility diameter. Defined in this way, the GF can be interpreted as apparent growth factor and is free of a possible systematic error introduced by condensational restructuring of the dry aerosol particle. This definition holds through the rest of the paper if not stated otherwise. However, for the interpretation of the apparent growth data one has to keep in mind that the actual morphology of the soot particles may differ for the same selected mobility diameter and can therefore have an effect on the observed values of the apparent GF.

\subsection{LACIS-mobile}

The mobile version of LACIS (LACIS-mobile) was used in this study. This setup is similar to LACIS as described by Stratmann et al. (2004), but features a shorter flow tube of $0.8 \mathrm{~m}$ length. Aerosol and sheath air were humidified applying water-to-gas Nafion humidifiers (aerosol: MH-110-12S4, sheath air: PH-30T-24KS, Perma Pure) to well defined dew point temperatures (reproducibility approx. $0.01 \mathrm{~K}$ ) before entering the flow tube. The dew point temperatures and the LACIS-mobile wall temperature determine the water vapor saturation in the flow tube. For the hygroscopic growth measurements described here, LACIS-mobile was operated in its sub-saturated mode of operation (Wex et al., 2005). In this mode the wall temperature $\left(20^{\circ} \mathrm{C}\right)$ was above the dew point temperature (between 19.7 and $19.95^{\circ} \mathrm{C}$ ) of the aerosol and the sheath air. The residence time of the particles in the flow tube is around two seconds, which is sufficient for particles to reach their wet equilibrium diameter (cf. Sect. 3.3).

At the end of the flow tube, the White-light Optical Particle Spectrometer (WOPS) measures the size of the grown particles (Kiselev et al., 2005). WOPS uses the scattering of the broad band light ( 350 to $800 \mathrm{~nm}$ ) and the wide range of scattering angles to avoid the ambiguity of size determination (the so-called Mie oscillations). The size of the single particles crossing the illuminating beam is retrieved from the response characteristic, which is calculated with the Mie theory for a multi-layered sphere (Bohren and Huffmann, 1983) accounting for size and complex refractive index of the dry aerosol, amount of soluble material (if known) and the thickness of water shell condensing on the particle. To calculate a response characteristic, the size of the non-soluble core 
(soot) is kept fixed and the size of the droplet is changing by condensation of a water shell. For the water shell, the refractive index was calculated as a volume proportional mixture of water and soluble material. The effective refractive index of the light absorbing soot core could be calculated using the Maxwell-Garnett approach for porous media (Dobbins and Megaridis, 1991) assuming the characteristic size of primary particles, number of primary particles per agglomerate (which is known from the mobility diameter measurement) and that a soot aggregate undergoes incomplete restructuring while being immersed into a water droplet. The calculated response curve is then corrected using the calibration of the instrument with PSL microspheres (Duke Scientific). Such calculations have been carried out for several test cases where aggregate size, fractal dimension, number and size of primary particles, degree of restructuring by immersion and amount of soluble coating have been varied within realistic limits.

To assess this possible systematic error, arising from the a priory assumption of the soot core morphology, we varied the effective refractive index of the soot core assuming different degrees of restructuring and calculated the corresponding variation of the response signal. For example, assuming the complete collapse of a $375 \mathrm{~nm}$ GFG-soot aggregate (with the highest possible packing factor of 0.63 ) would result in an effective complex refractive index (using the Maxwell-Garnett approach) of $1.66+0.41 \mathrm{i}$, which would produce a systematic overestimation of the apparent GF evaluated with such response curve. The systematic discrepancy between the apparent GF values calculated with these two refractive indices is below $10 \%$ for a GF of 1.1 and below $5 \%$ for a GF of 2 .

We found that the influence of the soot core morphology and the presence of the soluble coating have a negligible effect on the particle optical properties as soon as the particle has acquired a water shell of detectable thickness. Therefore, we have abandoned the fractal formalism of the soot core aggregate replacing it with the simplified model of a two-layer sphere. For the complex refractive index of the soot core a value of $1.74+0.65 \mathrm{i}$ has been assumed, while the refractive index of the water shell has been kept at 1.33.

The relative humidity (RH) in LACIS-mobile was calibrated as described in detail in Wex et al. (2005). Briefly, ammonium sulfate particles of known dry sizes (size-selected by a DMA) were send through the flow tube for a certain fixed wall temperature. The grown particle size at the end of the flow tube was detected with the WOPS for several set dew point temperatures. The wet particle diameters were determined applying a refractive index following the volume mixing rule for the diluted ammonium sulfate particles. For the so determined wet diameter the related RH was calculated via Köhler theory applying the water activity after Young and Warren (1992) and for a droplet molality above $0.8 \mathrm{~mol} \mathrm{~kg}^{-1}$ a fit to the data of Low (1969).

\subsection{HTDMA}

The hygroscopic growth of the particles was also measured with a HTDMA (Buchholz, 2007). 150 or $200 \mathrm{~nm}$ particles were size-selected with a first DMA from the dried polydisperse aerosol. The monodisperse aerosol and the sheath air of a second DMA were humidified at room temperature $\left(25^{\circ} \mathrm{C}\right)$ using gas-to gas humidifiers (Perma Pure Nafion, MH-Series) to almost the same RH value; with the sheath air being at slightly higher RH. The second DMA (measuring the size of the conditioned particles) is placed in an insulated box and was cooled to $20^{\circ} \mathrm{C}$. Before entering the second DMA both aerosol and sheath air were cooled down to this temperature and thus the RH increased to its final value to which they were exposed for approximately $20 \mathrm{~s}$ (Lang-Yona et al., 2010). To determine the RH inside the second DMA, Vaisala HMP235 sensors measured the RH and temperature outside the insulation area. The temperatures of the air flows inside the insulation box were measured with PT100 sensors directly before entering and immediately after leaving the second DMA. With the temperature and RH measured outside the absolute humidity in the air streams is calculated. Assuming the absolute humidity being constant, the RH in the cooled (second) DMA can be calculated from the temperature measured inside the cooled area. For RH calibration ammonium sulfate aerosol was used, following the procedure analogous to the description for LACIS-mobile (see above).

\subsection{VHTDMA}

Also a VHTDMA was applied to investigate the hygroscopic and volatility behavior of soot particles (Villani et al., 2008). Particles with $150 \mathrm{~nm}$ in diameter were selected from the polydisperse aerosol using a first DMA. The RH in the first DMA was below $20 \%$. The VHTDMA used has a thermodenuder section followed by a humidifier section between the first and a second DMA. The aerosol flow can be led through both sections or bypass either one, resulting in either volatility or hygroscopicity or combined volatility/hygroscopicity measurements. The residence time in the conditioned section is $12 \mathrm{~s}$. If the humidifier section was used, the sheath air of the second DMA was humidified; otherwise, it was kept dry. Both DMAs run as closed loop systems, and their flows are adjusted by means of flow controllers. Water-to-gas nafion humidifiers are used to condition the sheath air of the second DMA (Perma Pure PH-60T-12SS) and the aerosol flow (Perma Pure MD-110-12S-4). The RH in the VHTDMA instrument was calibrated analogously to LACIS-mobile with ammonium sulfate particles (see above). Capacitance humidity sensors (Rotronic, HygroClip SC05) are applied to monitor the RH. The size of the grown particles was determined applying a mode fitting routine. 
Table 2. Overview of experimental conditions and results of NAUA experiments during IN-11. The growth factor (GF) of $250 \mathrm{~nm}$ particles at $98.4 \% \mathrm{RH}$ is given for LACIS-mobile, if not mentioned otherwise. The activated fraction (AF) at a certain supersaturation (SS) is given, if no complete activation was observed. For complete activation the critical diameter $\left(d_{\mathrm{c}}\right)$ is given at a supersaturation of $0.24,0.27$ or $0.30 \%$, respectively.

\begin{tabular}{|c|c|c|c|c|c|}
\hline Generator & $\begin{array}{l}\text { Carrier } \\
\text { gas/OC- } \\
\text { content }\end{array}$ & Coating & Hygroscopic growth & Activation & $\begin{array}{l}\text { OC fraction from filter } \\
\text { analysis in wt } \%^{*}\end{array}$ \\
\hline GFG & Argon & Uncoated & $\begin{array}{l}\text { Not observed, } \\
\text { shrinking (HTDMA) }\end{array}$ & $\begin{array}{l}\mathrm{AF}=0.27 \text { at } \\
\mathrm{SS}=0.97 \pm 0.04 \% \\
d_{p, 0}=175 \mathrm{~nm}\end{array}$ & $12 \pm 9 \%$ \\
\hline GFG & Nitrogen & Uncoated & $\begin{array}{l}\text { Not observed, } \\
\text { shrinking (HTDMA) }\end{array}$ & $\begin{array}{l}\mathrm{AF}=0.04 \text { at } \\
\mathrm{SS}=0.97 \pm 0.04 \% \\
d_{p, 0}=175 \mathrm{~nm}\end{array}$ & \\
\hline GFG & Argon & Succinic acid & $\begin{array}{l}\mathrm{GF}=1.11 \pm 0.01 \\
(\mathrm{RH}=98.4 \pm 0.1 \%) \\
\text { shrinking }(\mathrm{HTDMA})\end{array}$ & $\begin{array}{l}d_{\mathrm{c}}=175 \mathrm{~nm} \\
\mathrm{SS}=0.30 \pm 0.01 \%\end{array}$ & $12+x^{* *} \%$ \\
\hline miniCAST & Min OC & Uncoated & Not observed & $\begin{array}{l}\mathrm{AF}=0.002 \text { at } \\
\mathrm{SS}=1.38 \pm 0.06 \% \\
d_{p, 0}=175 \mathrm{~nm}\end{array}$ & $32 \pm 4 \%$ \\
\hline miniCAST & Med OC & Uncoated & Not observed & $\begin{array}{l}\mathrm{AF}=0.006 \text { at } \\
\mathrm{SS}=1.03 \pm 0.04 \% \\
d_{p, 0}=175 \mathrm{~nm}\end{array}$ & $78 \pm 2 \%$ \\
\hline miniCAST & Max OC & Uncoated & Not observed & $\begin{array}{l}\mathrm{AF}=0.007 \text { at } \\
\mathrm{SS}=1.03 \pm 0.04 \% \\
d_{p, 0}=175 \mathrm{~nm}\end{array}$ & $>80 \%$ \\
\hline $\operatorname{miniCAST}$ & Med OC & Succinic acid & Not observed & $\begin{array}{l}\mathrm{AF}=0.3 \text { at } \\
\mathrm{SS}=1.03 \pm 0.04 \% \\
d_{p, 0}=175 \mathrm{~nm}\end{array}$ & $78+x^{* *} \%$ \\
\hline $\operatorname{miniCAST}$ & Min OC & Sulfuric acid & $\begin{array}{l}\mathrm{GF}=1.15 \pm 0.01 \\
(\mathrm{RH}=98.4 \pm 0.1 \%)\end{array}$ & $\begin{array}{l}d_{\mathrm{c}}=215 \mathrm{~nm} \\
\mathrm{SS}=0.27 \pm 0.01 \%\end{array}$ & $32 \pm 4 \%$ \\
\hline miniCAST & Med OC & Sulfuric acid & $\begin{array}{l}\mathrm{GF}=1.37 \pm 0.01 \\
(\mathrm{RH}=98.4 \pm 0.1 \%)\end{array}$ & $\begin{array}{l}d_{\mathrm{c}}=183 \mathrm{~nm} \\
\mathrm{SS}=0.24 \pm 0.01 \%\end{array}$ & $78 \pm 2 \%$ \\
\hline $\operatorname{miniCAST}$ & Max OC & Sulfuric acid & $\begin{array}{l}\mathrm{GF}=1.91 \pm 0.03 \\
(\mathrm{RH}=98.4 \pm 0.1 \%)\end{array}$ & $\begin{array}{l}d_{\mathrm{c}}=151 \mathrm{~nm} \\
\mathrm{SS}=0.27 \pm 0.01 \%\end{array}$ & $>80 \%$ \\
\hline
\end{tabular}

* OC values: personal communication C. Linke, OC fraction determined following the method VDI 2465 (1999).

** $x$ stands for the additional, but not quantified, OC fraction due to the succinic acid coating.

\section{$2.7 \quad \mathrm{CCNC}$}

Two streamwise thermal gradient cloud condensation nucleus counters (CCNC, Roberts and Nenes, 2005) were applied to investigate the activation of the particles. In this instrument the inlet flow is split into a particle-free sheath air flow, which is kept particle-free via a filter and an aerosol flow. Only the sheath air is humidified before entering the flow tube and surrounds the aerosol at the centerline. The streamwise temperature gradient applied in the flow tube determines the supersaturation to which the particles are exposed. The residence time in the column is about $12 \mathrm{~s}$ at the applied flow rate of $500 \mathrm{ml} \mathrm{min}^{-1}$ (Rose et al., 2008) with an exposure time to the maximum supersaturation of about $2 \mathrm{~s}$ (Snider et al., 2010). If the supersaturation is high enough to activate the particles into droplets, the number of these is detected at the end of the flow tube with an OPC. The CCNC is either used to measure saturations scans, meaning that the particle diameter is kept constant and the saturation is varied, or to measure diameter scans for which the saturation is fixed and the diameter is varied. In parallel to the CCNC a total particle counter was run, so that the activated particle fraction $(\mathrm{AF})$ can be calculated by dividing the activated by the total particle number. The firstly mentioned saturation scan results in a critical supersaturation, which by definition is the saturation, at which $50 \%$ of the particles become activated (AF equal 0.5). Analogously, a diameter scan allows for the detection of the critical diameter. However, this is only possible if full activation is reached within the available diameter and saturation matrix, which was not always the case for the pure soot particles. In the work presented here we run both diameter and saturation scans.

Ammonium sulfate particles were used to calibrate the supersaturation reached in the CCNC (Snider et al., 2010). Calibration measurements were repeated at least every fourth day. The instrument worked very stable with variability 
below $5 \%$ relative. In the data analysis the mean value of the calibration was applied.

\subsection{AMS}

A HR-TOF-AMS (Aerodyne Research Inc.) connected to the NAUA chamber was used to qualitatively characterize the coatings. The AMS is described in detail in Jayne et al. (2000), and DeCarlo et al. (2006). Briefly the AMS allows the mass spectrometric online investigation of aerosol particle composition after substantial reduction of the gas phase. The AMS was calibrated for ionization efficiency with $\mathrm{NH}_{4} \mathrm{NO}_{3}$ aerosol and particle size calibrated using polystyrol latex (PSL, Duke Scientific Corporation, Palo Alto CA) standards of different sizes between $81 \mathrm{~nm}$ and $596 \mathrm{~nm}$. For evaluation of the mass spectra the standard software package Squirrel provided by Aerodyne Research Inc. was applied.

\section{Results and discussion}

An overview of all experiments is given in Table 2 and their results are presented in the following sections according to the soot type. The hygroscopic growth of the different particle types is presented in the growth factor notation. No corrections regarding the particle shape were done, because no information on particle shape is available.

\subsection{Uncoated soot}

For uncoated CAST-soot particles hygroscopic growth was not observed for any OC-content.

Also the GFG-soot did not show hygroscopic growth in the LACIS-mobile measurements with either one of the carrier gases. Measurements with the HTDMA and VHTDMA (Fig. 2) indicated even a shrinking with increasing RH by up to $5 \%(\mathrm{GF}=0.95)$, which is likely due to compaction of the particles when getting into contact with water at $\mathrm{RH}$ $>35 \%$. In LACIS no shrinking was observed, which could be due to the white light OPC not being sensitive to the structural change of the absorbing soot aggregate (see discussion in Sect. 2.4).

Activation was also not observed for the different CASTsoot types and for the GFG-soot with nitrogen as carrier gas at the highest supersaturation of about $1.5 \%$ reached in the $\mathrm{CCN}$ instrument. However, the activated fraction did reach up to $95 \%$ at a supersaturation of $1.5 \%$ if argon was employed as carrier gas in the GFG-soot production (see Fig. 3). With increasing particle diameter the activation curves did shift to lower supersaturation. The observed shift could be due to the Kelvin effect. However, neither morphology nor size dependent chemistry can be excluded completely, as the measured and calculated critical supersaturation values lie within the accuracy of the CCNC instrument ( $5 \%$ relative).

At present we can only speculate on the influence of the carrier gas on the activation of GFG-soot. One

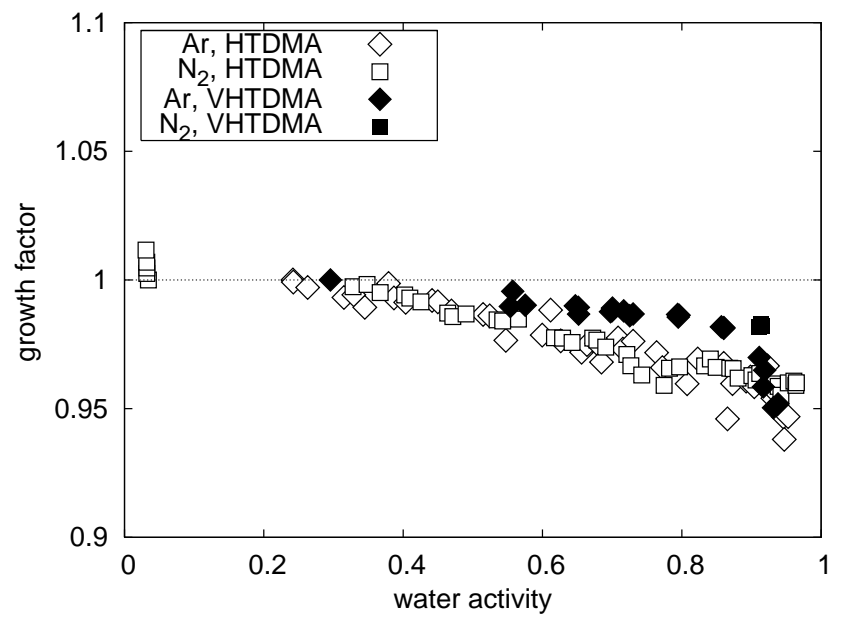

Fig. 2. Hygroscopic growth of GFG-soot measured with HTDMA (open symbols) and VHTDMA (filled symbols), carrier gases argon (diamonds) and nitrogen (squares).

hypothesis is based on the different gas properties, e.g. thermal conductivity and dielectric constant of the gases Argon $(0.01772 \mathrm{~W} /(\mathrm{mK}), 1.000513)$ and Nitrogen $(0.02583 \mathrm{~W} /(\mathrm{mK}), 1.00058)$. The different gas properties might result in a different spark temperature of the GFG. This could cause differences in the structure of the primary particles and thus influence the activation properties of the agglomerate. A second hypothesis is based on the purity of the carrier gases applied. We chose for both gases the same high purity of 6.0. Despite the high purity of $99.999999 \%$, there are still $0.000001 \%$ other gases, which might differ for Argon and Nitrogen due to different production pathways. These other gases could be involved in the particle formation process influencing the soluble particle fraction.

Neither hygroscopicity nor droplet activation of the uncoated CAST-soot particles depend on the OC content (see Table 2). The organic substances on the soot are possibly not wettable or miscible with water. This is consistent with findings by Dusek et al. (2006), who observed an increased activation supersaturation of soot particles after having coated them with an organic substance (hexadecanol, $\mathrm{C}_{16} \mathrm{H}_{34} \mathrm{O}$ ). They attributed this to a reduced wettability of the particles due to the organic coating.

\subsection{Succinic acid coated soot}

CAST-soot with medium OC-content and GFG-soot with argon as carrier gas were coated with succinic acid (see Table 1). No hygroscopic growth was observed for the coated CAST-soot by all three instruments. As depicted in Fig. 4, a shrinking of the coated GFG-soot was observed with the HTDMA. Hygroscopicity measurements of the same soot with LACIS-mobile gave a growth factor of 1.11 at $98.4 \%$ RH for particles with 375 and $500 \mathrm{~nm}$ dry diameter. The observed difference is most likely due to the different "humidity 


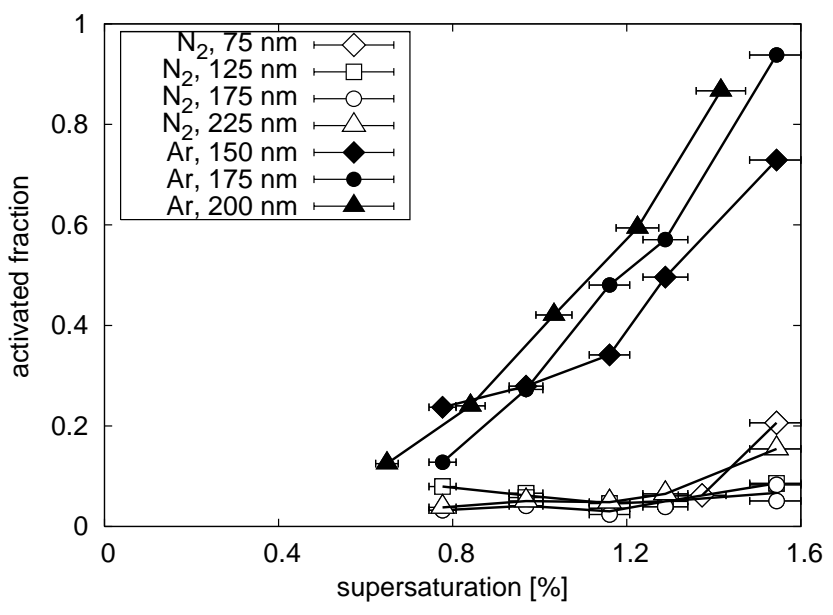

Fig. 3. Activation of GFG-soot measured with CCNC, carrier gases argon (filled symbols) and nitrogen (open symbols).

history" of the particles. Gas-to-gas humidifier are applied in the HTDMA, whereas water-to-gas humidifier are utilized in LACIS-mobile. Using the latter, particles are wetted at up to $100 \%$ RH and deliquescence of succinic acid occurs (at $99 \%$ RH, Wex et al., 2007). In contrast, gas-to-gas humidifiers do not reach RHs high enough to reach deliquescence of succinic acid. Therefore LACIS-mobile measured probably soot with a succinic acid solution and the HTDMA soot coated with solid succinic acid.

For succinic acid coated GFG-soot an increase of the hygroscopic growth (applying LACIS-mobile) and the activated fraction compared to the uncoated soot was observed. In contrary, the coating of CAST-soot with succinic acid increased only the activated fraction and had no influence on the hygroscopic growth. Also the coated GFG-soot depicted a higher activated fraction at the same supersaturation than the coated CAST-soot (Fig. 5). For both soot types the coating section was operated under similar conditions (see Table 1), thus should have led to a similar coating thickness of the particles. The difference between CAST- and GFGsoot could be explained by the formation of a mixed liquid layer of succinic acid and organics on the CAST-soot particles in contrast to adsorption of succinic acid to the almost pure black carbon surface of the GFG-soot. As a result of such a process, the contribution of succinic acid to hygroscopic growth and activation could be reduced or suppressed leading to undetectable hygroscopic growth and only partial activation.

\subsection{Sulfuric acid coated soot}

CAST-soot with low, medium and high OC-content was coated with sulfuric acid (see Table 1). Hygroscopic growth increased with increasing OC-content, as depicted in Fig. 6. This general trend is in agreement for all instruments. However, considering the instrumental error bars discrepancies

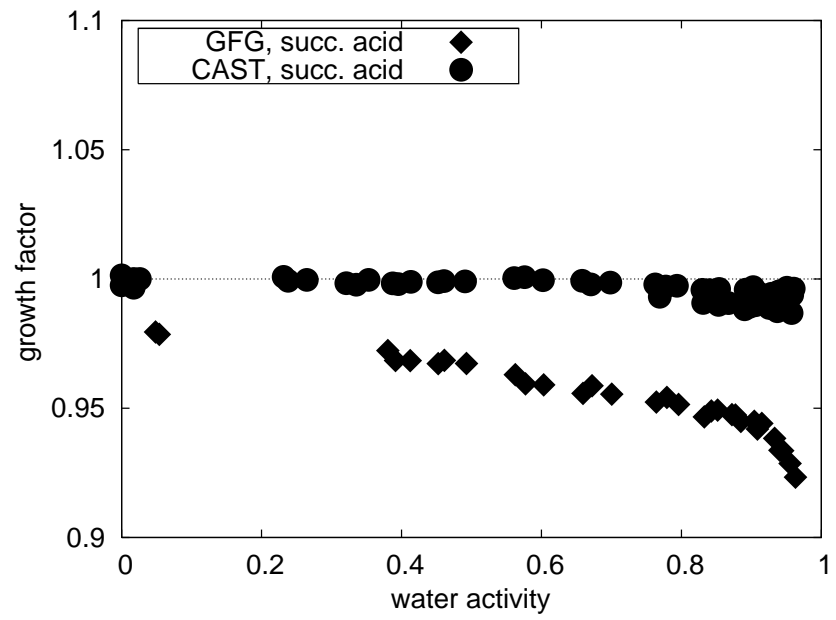

Fig. 4. Hygroscopic growth of succinic acid coated GFG-soot (diamonds, carrier gas argon) and CAST-soot (circles, medium OCcontent) measured by the HTDMA.

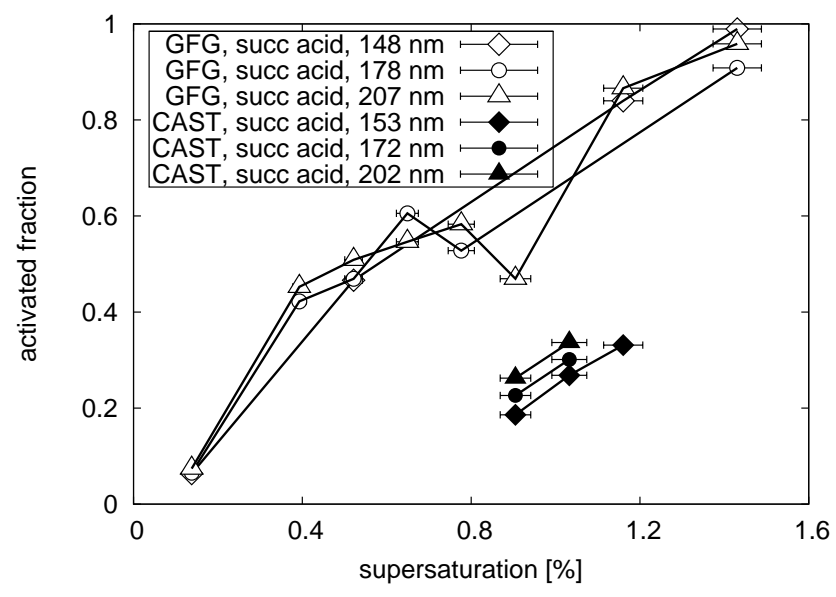

Fig. 5. Activation of succinic acid coated GFG-soot (carrier gas argon) and CAST-soot (medium OC-content).

are remaining. At the moment we have no explanation why some measurements of sulfuric acid coated CAST-soot deviate, while all others agree within the error bars. We can exclude malfunction of any instrument, since repeated calibrations of the relative humidity (and for LACIS-mobile the OPC) showed a high reproducibility for all instruments. Therefore one might speculate, that the chemical composition (OC-content, amount of sulfuric acid, ...) is a function of the particle size. Then the measured GF's would be different, because the instruments selected different mobility sizes (HTDMA $150 \mathrm{~nm}$, VHTDMA 100/150 nm and LACISmobile $250 \mathrm{~nm}$ ), which was due to instrumental limitations.

The residence time does not seem to be a critical issue here, as the GF of CAST-soot with high OC-content (cf. Fig. 6) measured with the VHTDMA (residence time about $12 \mathrm{~s}$ ) and LACIS-mobile (about $2 \mathrm{~s}$ ) is higher than that 


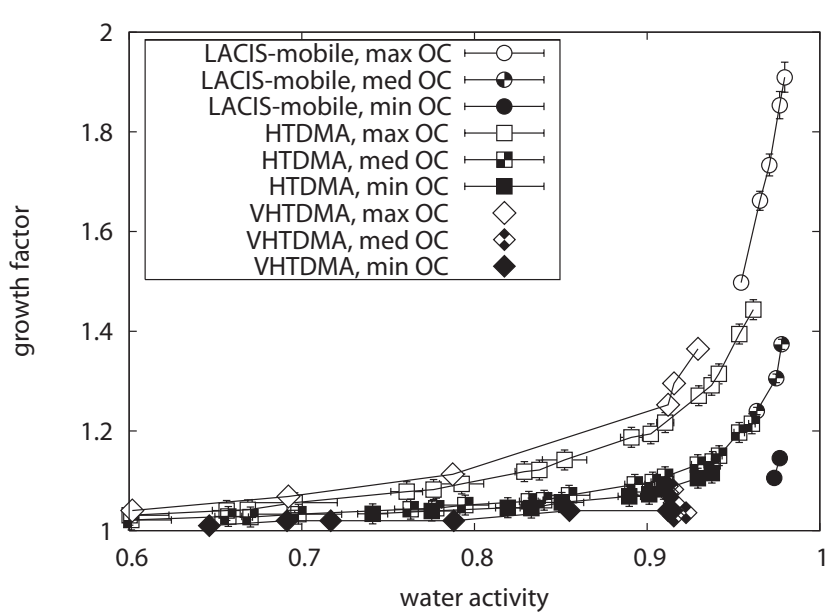

Fig. 6. Hygroscopic growth of sulfuric acid coated CAST-soot with low (filled), medium (partial filled) and high (open) OC-content. Applied instruments: LACIS-mobile (circles), HTDMA (squares) and VHTDMA (diamonds).

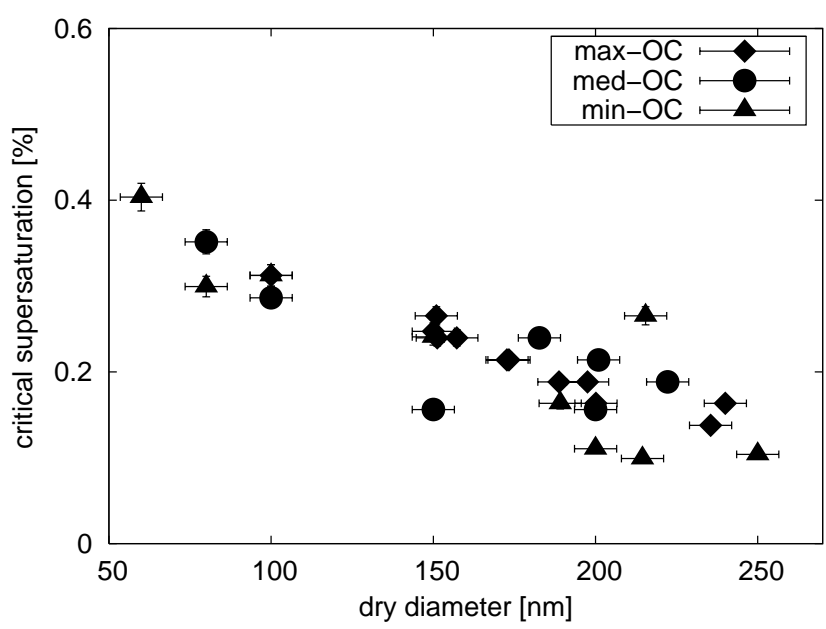

Fig. 7. Activation of sulfuric acid coated CAST-soot with low (triangles), medium (circles) and high (diamonds) OC-content.

measured with the HTDMA, which has the longest residence time (about $20 \mathrm{~s}$ ). This implies that measurements performed at longer residence time result in lower GFs. This is different from the findings by Duplissy et al. (2009) who observed an increase in the GF with increasing residence time. For CASTsoot medium OC-content HTDMA and LACIS-mobile agree well despite their different residence time. For CAST-soot with low OC-content there are unfortunately no overlapping measurement points with LACIS-mobile.

We observed an increasing hygroscopic growth with increasing OC content. This could be caused by a reactive uptake of sulfuric acid by the OC, leading to an increasing amount of soluble material on the particles with increasing OC-content. This could have caused enhanced growth factors for the higher OC-contents due to the dependence of the

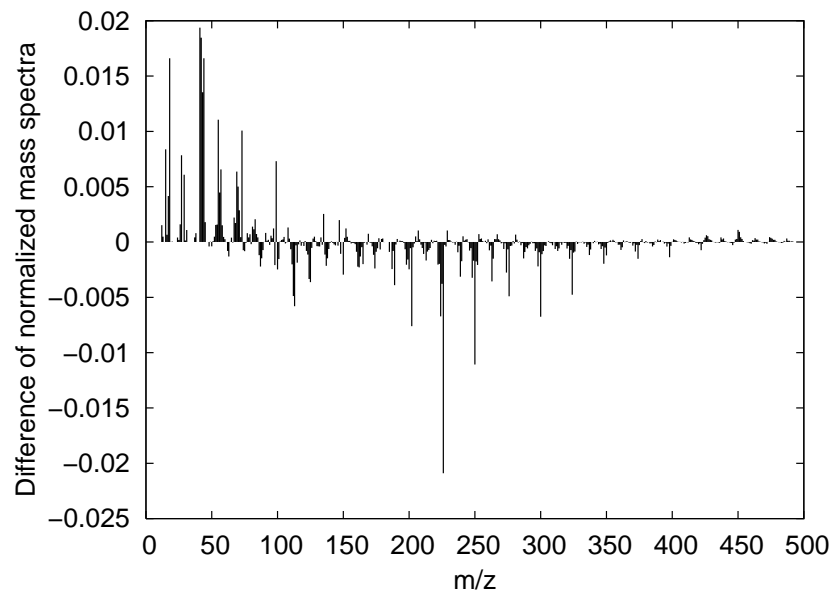

Fig. 8. Difference mass spectrum of sulfuric acid coated CAST-soot (medium OC-content) and uncoated CAST-soot.

formation of the soluble material on the OC-content. Our results are phenomenologically similar to findings from Khalizov et al. (2009), who investigated flame soot. They observed no water uptake below $100 \%$ for untreated particles, but water uptake for the sulfuric acid coated particles. The influence of soot morphology on the observed growth factors for different OC-contents should not be an issue in this experiment for the following two reasons: firstly, as mentioned in the experimental section, the mobility selection of the dry aerosol particles took place after coating the polydisperse soot aggregate population, meaning that all soot aggregates were already compacted prior to mobility selection. Secondly, as it was shown in Kiselev et al. (2010), the amount of coating substance condensed on the agglomerates of a given mobility size is a function of the vapor pressure of the coating substance only (or, the temperature in the coating furnace, which was constant for the experiments) and is independent of the aggregate structure.

Coating with sulfuric acid caused complete activation of the CAST-soot without dependence on the OC-content (cf. Fig. 7).

Measurements of the chemical composition were carried out by means of an HR-ToF-AMS. Polycyclic aromatic hydrocarbons $(\mathrm{PAH})$ were found in the fraction of the $\mathrm{OC}$ of the CAST soot volatile at $600^{\circ} \mathrm{C}$. PAHs are slightly soluble or even insoluble in water and the solubility decreases with increasing molecular mass. The comparison of the mass spectra of untreated soot and sulfuric acid coated soot showed that the fraction of mass peaks with $\mathrm{m} / z>150$ dropped and the fraction with $m / z<150$ increased, as illustrated in a difference mass spectrum (Fig. 8). Probably the sulfuric acid reacts with the PAHs (as illustrated in Fig. 9) and forms products with lower molecular weight than the initial PAHs. These products could have a higher solubility in water than the initial PAHs. As a consequence, the hygroscopic growth 


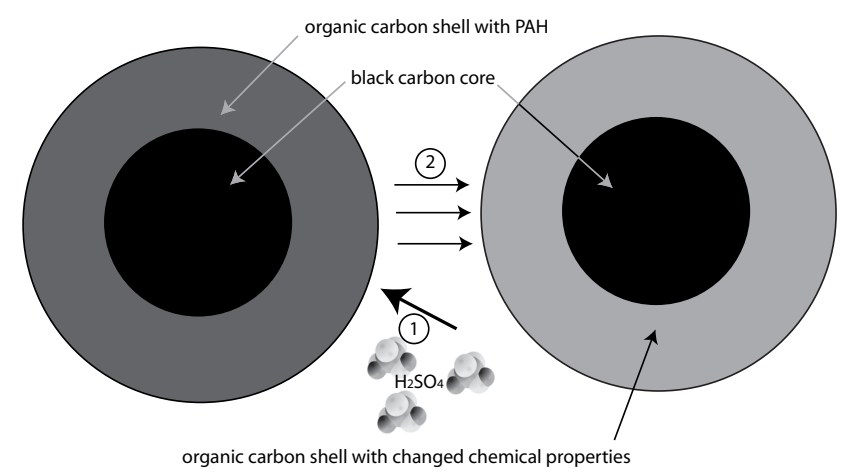

Fig. 9. Illustration for reactive uptake of sulfuric acid and change of chemical composition of the $\mathrm{OC}$ due to the reaction of sulfuric acid and PAHs.

and activated fraction increased due to (a) the products of this reaction and (b) the unconsumed coating fraction itself.

Reactions of sulfuric acid with PAH have been previously observed (Granella and Clonfero, 1991; Banoglu and Duffel, 1999, and references therein). Whether the specific reactions described in Granella and Clonfero (1991) and Banoglu and Duffel (1999) apply to our systems can only be speculated. Sulfuric acid coated flame soot was also investigated by Zhang et al. (2008). In contrast to our results, they found no hints for interactions of sulfuric acid with any substance on the soot. The particle mass before coating was identical to the mass found after the removal of the coating. However, note that Zhang et al. (2008) generated the soot particles with a different burner type, which produces flame soot with a lower OC-content (about $1 \%$ Pagels et al., 2009) than used in our experiments.

In contrast to the CAST-soot, no PAHs were found on the GFG-soot. A substance condensed on the GFG-soot would increase the activated fraction and hygroscopic growth by itself. A comparison of the AMS spectra of untreated and succinic acid coated GFG-soot gave no hints for an interaction of succinic acid and substances at the GFG-soot as the difference mass spectrum was identical to the mass spectrum of succinic acid.

\section{Summary and conclusions}

The hygroscopic growth and cloud droplet activation of uncoated and coated soot particles were investigated. A flame soot generator (miniCAST) and a spark soot generator (GFG1000) were utilized to generate soot particles. CAST-soot particles with either low, medium or high OC-content were produced and nitrogen or argon were used as carrier gases for the GFG-1000. Investigations were conducted on untreated soot particles and on soot coated with either succinic or sulfuric acid.

Neither hygroscopic growth nor activation were observed for the untreated soot particles - with one exception; for
GFG-soot with argon as carrier gas activation was observed. The influence of the carrier gas on the activation behavior might be caused by the different properties of the carrier gases themselves or by different trace impurities in the gas bottles.

The activated fraction of CAST- and GFG-soot was increased by coating with succinic acid. For succinic acid coated CAST-soot, no water uptake at subsaturation was observed. For GFG-soot coated with succinic acid hygroscopic growth was observed with LACIS-mobile, but not with the HTDMAs. The instrumental discrepancy is explained by the "humidity history" of the particles, i.e. LACIS-mobile measured soot with deliquescent succinic acid whereas the HTDMAs measured solid succinic acid on the soot. The difference between CAST- and GFG-soot could be explained by the formation of a mixed liquid layer of succinic acid and organics on the CAST-soot particles in contrast to adsorption of succinic acid to the almost pure black carbon surface of the GFG-soot.

Sulfuric acid was applied to coat CAST-soot. An increase of the hygroscopic growth was observed with increasing OCcontent. However, no dependence of the cloud droplet activation on the OC-content was observed. AMS-measurements showed the presence of PAHs, the amount of which was decreased by coating with sulfuric acid. At the same time the fraction of lighter mass peaks increased. This led to the conclusion that the amount of PAHs and their chemical processing by the uptake of reactive substances like sulfuric acid may play a key role in understanding hygroscopic growth and droplet activation of flame soot. Sulfuric acid acts in two ways: (a) it reacts with PAHs forming thereby lighter molecular weight products with changed hygroscopic properties and (b) the amount of sulfuric acid which is not consumed in the reaction increases the hygroscopicity by itself.

Acknowledgements. We are grateful for financial support by the Helmholtz Virtual Institute "Aerosol Cloud Interaction" (VI-ACI). Traveling expenses of the LaMP group as well as the VHTDMA transport were funded by the ESF programme INTROP, which we would like to acknowledge here. Furthermore, we would like to thank Stefan Benz for coordinating the IN-11 campaign at the AIDA facility.

Edited by: D. J. Cziczo

\section{References}

Albrecht, B.: Aerosol, cloud microphysics, and fractional cloudiness, Science, 245, 1227-1230, 1989.

Andreae, M. O. and Rosenfeld, D.: Aerosol-cloud-precipitation interactions. Part 1. The nature and sources of cloud-active aerosols, Earth-Sci. Rev., 89, 13-41, 2008.

Banoglu, E. and Duffel, M.: Importance of peri-interactions on the stereospecificity of rat hydroxysteroid sulfotransferase STa with 1-arylethanols, Chem. Res. Toxicol., 12, 278-285, 1999. 
Bilde, M., Svenningsson, B., Monster, J., and Rosenorn, T.: EvenOdd alternation of evaporating rates and vapor pressure of C3C9 dicarboxylic acid aerosols, Environ. Sci. Technol., 37, 13711378, 2003.

Bohren, C. F. and Huffmann, D. R.: Absorption and Scattering of Light by Small Particles, Wiley, New York, 1983.

Bond, T., Streets, D.G., Yarber, K., Nelson, S., Woo, J.-H., and Klimont, Z.: A technology-base global inventory of black and organic carbon emissions from combustion, J. Geophys. Res., 109, D14203, doi:10.1029/2003JD003697, 2004.

Buchholz, A.: Entwicklung eines Geräts zur Untersuchung des hygroskopischen Wachstums von organischen Aerosolen, Master's thesis, Department of Chemistry, University of Cologne, Cologne, Germany, 2007.

Chebbi, A. and Carlier, P.: Carboxylic acids in the troposphere, occurence, sources, and sinks: a review, Atmos. Environ., 30, 42334249, 1996.

Cooke, W. and Wilson, J.: A global black carbon aerosol model, J. Geophys. Res., 101, 19395-19409, 1996.

Cooke, W., Liousse, C., Cachier, H., and Feichter, J.: Construction of a $1^{\circ} \times 1^{\circ}$ fossil fuel emission data set for carbonaceous aerosol and implementation and radiative impact in the ECHAM4 model, J. Geophys. Res., 104, 22137-22162, 1999.

Crawford, I., Möhler, O., Schnaiter, M., Saathoff, H., Liu, D., McMeeking, G., Linke, C., Flynn, M., Bower, K. N., Connolly, P. J., Gallagher, M. W., and Coe, H.: Studies of propane flame soot acting as heterogeneous ice nuclei in conjunction with single particle soot photometer measurements, Atmos. Chem. Phys., 11, 9549-9561, doi:10.5194/acp-11-9549-2011, 2011.

DeCarlo, P. F., Kimmel, J. R., Trimborn, A., Northway, M. J., Jayne, J. T., Aiken, A. C., Gonin, M., Fuhrer, K., Horvath, T., Docherty, K. S., Worsnop, D. R., Jimenez, J. L.: Fielddeployable, high-resolution, time-of-flight aerosol mass spectrometer, Anal. Chem., 78, 8281-8289, 2006.

Dobbins, R. A., and Megaridis, C. M.: Absorption and Scattering of Light by Polydisperse Aggregates, Appl. Optics, 30, 4747-4754, 1991.

Dusek, U., Reischl, G., and Hitzenberger, R.: CCN activation of pure and coated carbon black particles, Environ. Sci. Technol., 40, 1223-1230, 2006.

Duplissy, J., Gysel, M., Sjogren, S., Meyer, N., Good, N., Kammermann, L., Michaud, V., Weigel, R., Martins dos Santos, S., Gruening, C., Villani, P., Laj, P., Sellegri, K., Metzger, A., McFiggans, G., Wehrle, G., Richter, R., Dommen, J., Ristovski, Z., Baltensperger, U. and Weingartner, E.: Intercomparison study of six HTDMAs: results and recommandations, Atmos. Meas. Tech., 2, 363-378, doi:10.5194/amt-2-363-2009, 2009.

Granella, M. and Clonfero, E.: The mutagenetic activity and polycyclic aromatic hydrocarbon content of mineral oils, Int. Arch. Occ. Environ. Health, 63, 149-153, 1991.

Gysel, M., Nyeki, S., Weingartner, E., Baltensperger, U., Giebl, H., Hitzenberger, R., Petzold, A., and Wilson, C.: Properties of jet engine combustion particles during the PartEmis experiment: hygroscopicity at subsaturated conditions, Geophys. Res. Lett., 30, 1566, doi:10.1029/2003GL016896, 2003.

Hagen, D., Trueblood, M., and White, D.: Hydration properties of combustion aerosols, Aerosol Sci. Technol., 10, 63-69, 1989.

Helsper, C., Mölter, W., Löffler, F., Wadenpohl, C., and Kaufmann, S.: Investigation of a new aerosol generator for the produc- tion of carbon aggregate particles, Atmos. Environ., 27A, 12711275, 1993.

Henning, S., Wex, H., Hennig, T., Kiselev, A., Snider, J., Rose, D., Dusek, U., Frank, G., Pöschl, U., Kristensson, A., Bilde, M., Tillamnn, R., Kiendler-Scharr, A., Mentel, T., Walter, S., Schneider, J., Wennrich, C., and Stratmann, F.: Soluble mass, hygroscopic growth, and droplet activation of coated soot particles during LACIS Experiment in November (LExNo), J. Geophys. Res., 115, D11206, doi:10.1029/2009JD012626, 2010.

Hitzenberger, R., Giebl, H., Petzold, A., Gysel, M., Nyeki, S., Weingartner, E., Baltensperger, U., and Wilson, C.: Properties of jet engine combustion particles during the PartEmis experiment. Hygroscopic growth at supersaturated conditions, Geophys. Res. Lett., 30, 1779, doi:10.1029/2003GL017294, 2003.

Horvath, H.: Atmospheric light absorption - a review, Atmos. Environ., 27A, 293-317, 1993.

Howard, P. H. and Meylan, W. M. (eds.): Handbook of Physical Properties of Organic Chemicals, CRC Press, Boca Raton, FL, USA, 3-4-3-522, 1997.

Hudson, J., Hallett, J., and Rogers, C.: Field and laboratory measurements of cloud-forming properties of combustion aerosols, J. Geophys. Res., 96, 10847-10859, 1991.

Ito, A. and Penner, J.: Historical emissions of carbonaceous aerosols from biomass and fossil fuel burning for the period 1870-2000, Global Biogeochem. Cy., 19, GB2028, doi:10.1029/2004GB002374, 2005.

Jacobson, M.: Climate response on fossil fuel and biofuel soot, accounting for soot's feedback to snow and sea ice albedo and emissivity, J. Geophys. Res., 109, 945, doi:10.1029/2004JD004, 2004.

Jayne, J., Leard, D., Zhang, X., Davidovits, P., Smith, K., Kolb, C., and Worsnop, D.: Development of an aerosol mass spectrometer for size and composition analysis of submicron particles, Aerosol Sci. Technol., 33, 49-70, 2000.

Jing, L.: Neuer Russgenerator für Verbrennungsteilchen zur Kalibrierung von Partikelmessgeräten, OFMET Info, 7, 1-5, 2000.

Junker, C. and Liousse, C.: A global emission inventory of carbonaceous aerosol from historic records of fossil fuel and biofuel consumption for the period 1860-1997, Atmos. Chem. Phys., 8, 1195-1207, doi:10.5194/acp-8-1195-2008, 2008.

Kanakidou, M., Seinfeld, J. H., Pandis, S. N., Barnes, I., Dentener, F. J., Facchini, M. C., Van Dingenen, R., Ervens, B., Nenes, A., Nielsen, C. J., Swietlicki, E., Putaud, J. P., Balkanski, Y., Fuzzi, S., Horth, J., Moortgat, G. K., Winterhalter, R., Myhre, C. E. L., Tsigaridis, K., Vignati, E., Stephanou, E. G., and Wilson, J.: Organic aerosol and global climate modelling: a review, Atmos. Chem. Phys., 5, 1053-1123, doi:10.5194/acp-51053-2005, 2005.

Khalizov, A., Zhang, R., Zhang, D., Xue, H., Pagels, J., and McMurry, P.: Formation of highly hygroscopic soot aerosols upon internal mixing with sulfuric acid vapor, J. Geophys. Res., 114, D05208, doi:10.1029/2008JD010595, 2009.

Kim, D., Wang, C., Ekman, A., Barth, M., and Rasch, P.: Distribution and direct radiative forcing of carbonaceous and sulfate aerosols in an interactive size-resolving aerosol-climate model, J. Geophys. Res., 113, D16309, doi:10.1029/2007JD009756, 2008.

Kiselev, A., Wex, H., Stratmann, F., Nadeev, A., and Karpushenko, D.: White-light optical particle spectrometer for insitu measurements of condensational growth of aerosol particles, 
Appl. Opt., 44, 4693-4701, 2005.

Kiselev, A., Wennrich, C., Stratmann, F., Wex, H., Henning, S., Mentel, T. F., Kiendler-Scharr, A., Schneider, J., Walter, S., Lieberwirth, I.: Morphological characterization of soot aerosol particles during LACIS Experiment in November (LExNo), J. Geophys. Res., 115, D11204, doi:10.1029/2009JD012635, 2010.

Lammel, G. and Novakov, T.: Water nucleation properties of carbon black and diesel soot particles, Atmos. Environ., 29, 813-823, 1995.

Lang-Yona, N., Rudich, Y., Mentel, Th. F., Bohne, A., Buchholz, A., Kiendler-Scharr, A., Kleist, E., Spindler, C., Tillmann, R., and Wildt, J.: The chemical and microphysical properties of secondary organic aerosols from Holm Oak emissions, Atmos. Chem. Phys., 10, 7253-7265, doi:10.5194/acp-10-7253-2010, 2010.

Low, R. D. H.: A Generalized Equation for Solution Effect in Droplet Growth, J. Atmos. Sci., 26, 608-610, 1969.

Meyer, N. and Ristovski, Z.: Ternary nucleation as a mechanism for the production of diesel nanoparticles: experimental analysis of the volantile and hygroscopic properties of diesel exhaust using the volatilization and humidification tandem differential mobility analyzer, Environ. Sci. Technol., 41, 7309-7314, 2007.

Mikhailov, E. F., Vlasenko, S. S., Krämer, L. and Niessner, R.,: Soot particle restructuring due to interaction with water droplets, J. Aerosol Sci., 30, S443-S444, doi:10.1016/S00218502(99)80233-X, 1999.

Möhler, O., Nink, A., Saathoff, H., Schaefers, S., Schnaiter, M., Schöck, W., and Schurath, U.: The Karlsruhe aerosol chamber facility AIDA: technical description and first results of homogeneous and heterogeneous ice nucleation experiments, in: Proceedings of Workshop on Ion-Aerosol-Cloud-Interactions (IACI); edited by: Kirkby, J., CERN 2001-007; Geneva, 18-20 April 2001, CERN, Geneva, 2001.

Möhler, O., Buttner, S., Linke, C., Schnaiter, M., Saathoff, H., Stetzer, O., Wagner, R., Krämer, M., Mangold, A., Ebert, V. and Schurath, U.: Effect of sulfuric acid coating on heterogeneous ice nucleation by soot aerosol particles, J. Geophys. Res., 110, D11210, doi:10.1029/2004JD005169, 2005.

Novakov, T., Ramanathan, V., Hansen, J., Kirchstetter, T., Sato, M., Siton, J., and Sathaye, J.: Large historical changes of fossilfuel black carbon aerosols, Geophys. Res. Lett., 30, 1324, doi:10.1029/2002GL016345, 2003.

Pagels, J., Khalizov, A., McMurry, P., and Zhang, R.: Processing of soot by controlled sulphuric acid and water condensation - mass and mobility relationship, Aerosol Sci. Technol., 43, 629-640, 2009.

Penner, J., Eddleman, H., and Novakov, T.: Towards the development of a global inventory for black carbon emissions, Atmos. Environ., 27A, 1277-1295, 1993.

Pitchford, M., Hudson, J., and Hallett, J.: Size and critical supersaturation for condensation of jet engine exhaust particles, J. Geophys. Res., 96, 20787-20793, 1991.

Pratsinis, S., Zeldin, M., and Ellis, E.: Source resolution of the fine carbonaceous aerosol by principal component - stepwise regression analysis, Environ. Sci. Technol., 22, 212-216, 1988.

Roberts, G. and Nenes, A.: A continuous-flow streamwise thermalgradient CCN chamber for atmospheric measurements, Aerosol Sci. Technol., 39, 206-221, 2005.
Rose, D., Gunthe, S. S., Mikhailov, E., Frank, G. P., Dusek, U., Andreae, M. O., and Pöschl, U.: Calibration and measurement uncertainties of a continuous-flow cloud condensation nuclei counter (DMT-CCNC): CCN activation of ammonium sulfate and sodium chloride aerosol particles in theory and experiment, Atmos. Chem. Phys., 8, 1153-1179, doi:10.5194/acp-8-11532008, 2008.

Schmidt-Ott, A.: New approaches to in situ characterization of ultrafine agglomerates, J. Aerosol Sci., 19, 553-563, doi:10.1016/0021-8502(88)90207-8, 1988.

Seinfeld, J. and Pandis, S.: Atmospheric Chemistry and Physics: from Air Pollution to Climate Change, 2 edn., Wiley, New York, USA, 1-1307, 2006.

Snider, J. R., Wex, H., Rose, D., Kristensson, A., Stratmann, F., Hennig, T., Henning, S., Kiselev, A., Bilde, M., Burkhart, M., Dusek, U., Frank, G. P., Kiendler-Scharr, A., Mentel, T. F., Petters, M. D., and Pöschl, U.: Intercomparison of cloud condensation nuclei and hygroscopic fraction measurements: Coated soot particles investigated during the LACIS Experiment in November (LExNo), J. Geophys. Res.-Atmos., 115, doi:10.1029/2009JD012618, 2010.

Stratmann, F., Kiselev, A., Wurzler, S., Wendisch, M., Heintzenberg, J., Charlson, R., Diehl, K., Wex, H., and Schmidt, S.: Laboratory studies and numerical simulations of cloud droplet formation under realistic supersaturation conditions, J. Atmos. Ocean. Technol., 21, 876-887, 2004.

Tegen, I., Koch, D., Lacis, A., and Sato, M.: Trends in the tropospheric aerosol loads and corresponding impact on direct radiative forcing between 1950 and 1990: a model study, J. Geophys. Res., 105, 26971-26989, 2000.

Tritscher, T., Juranyi, Z., Martin, M., Chirico, R., Gysel, M., Heringa, M. F., DeCarlo, P. F., Sierau, B., Prevot, A. S. H., Weingartner, E., Baltensperger, U.: Changes of hygroscopicity and morphology during aging of diesel soot, Environ. Res. Lett., 6, 034026, doi:10.1088/1748-9326/6/3/034026, 2011.

Twomey, S.: Pollution and the planetary albedo, Atmos. Environ., 8, 1251-1256, 1974.

VDI 2465: Measurement of soot (Ambient Air) - thermographical determination of elemental carbon after thermal desorption of organic carbon, Kommission Reinhaltung der Luft im VDI und DIN - Normenausschuss KRdL, ICS, 13.040.20, Beuth Verlag, Berlin, Germany, 1999.

Villani, P., Picard, D., Michaud, V. P., and Wiedensohler, A.: Design and validation of a Volatility Hygroscopic Tandem Differential Mobility Analyzer (VH-TDMA) to characterize the relationships between the thermal and hygroscopic properties of atmospheric aerosol particles, Aerosol Sci. Technol., 42, 729-741, 2008.

Weingartner, E., Burtscher, H., and Baltensperger, U.: Hygroscopic properties of carbon and diesel soot particles, Atmos. Environ., 31, 2311-2327, 1997.

Wex, H., Kiselev, A., Stratmann, F., Zoboki, J., Heintzenberg, J., and Brechtel, F.: Measured and modeled equilibrium sizes of $\mathrm{NaCl}$ and $\left(\mathrm{NH}_{4}\right)_{2} \mathrm{SO}_{4}$ particles at relative humidities up to $99.1 \%$, J. Geophys. Res., 110, D21212, doi:10.1029/2004JD005507, 2005.

Wex, H., Ziese, M., Kiselev, A., Henning, S., and Stratmann, F.: Deliquescence and hygroscopic growth of succinic acid particles measured with LACIS, Geophys. Res. Lett., 34, D11206, doi:10.1029/2009JD012626, 2007. 
Wiltzius, P.: Hydrodynamic behavior of fractal aggregates, Phys. Rev. Lett., 58, 71-713, doi:10.1103/PhysRevLett.58.710, 1987.

Wollf, G. and Korsog, P.: Estimates of the contribution of sources to inhalable particulate concentrations in Detroit, Atmos. Environ., 19, 1399-1409, 1985.

Young, K. C., and Warren, A. J.: A Reexamination of the Derivation of the Equilibrium Supersaturation Curve for Soluble Particles, J. Atmos. Sci., 49, 1138-1143, 1992.
Zhang, R., Khalizov, A., Pagels, J., Zhang, D., Xue, H., and McMurry, P.: Variability in morphology, hygroscopicity, and optical properties of soot aerosols during atmospheric processing, Proc. Natl. Acad. Sci. USA, 105, 10291-10296, 2008. 